\title{
La Geografía y el poder. Territorialización del poder en Colombia El caso FARC -De Marquetalia al Caguán-
}

José Luis Cadena Montenegro*

Resumen: Este artículo es una síntesis de un trabajo de maestría sustentado en el mes de junio de 2002. Se trata de una investigación en la línea de Geopolítica, sobre un tema de actualidad que emplea los multimétodos como guía metodológica y que pretende constituirse en aporte para confrontar los problemas territoriales y espaciales que aquejan a Colombia como consecuencia del conflicto armado que subsiste por casi medio siglo. Se creyó que despejando de autoridad un terri torio, se iniciaría un proceso de reconciliación, pero los hechos indican todo lo contrario y se perdió tiempo precioso al entregar el Estado la soberanía de la que se llamó, zona de distensión del Caguán. Es posible que desde la Antropología, la Sociología y la Ciencia Política, el tema haya sido abordado, pero desde la Geogra fía, este trabajo de tipo exploratorio pretende despertar el interés de los estadistas y de los estrategas por uno de los elementos constitutivos del Estado: el territorio.

Palabras clave: zona de distensión, Geografía, Geopolítica, Geoestrategia, Esta do, Nación, territorio, espacio, soberanía, dominio, poder, unidad territorial, des peje, fronteras, corredores de movilidad, bienes públicos, población, balcanización.

(Aceptado noviembre 2002).

\footnotetext{
* Profesional en Ciencias Militares, Magister en Ciencia Política, Magister en Planeación Socioeconómica, Consultor en Defensa y Seguridad y Magister en Geografía énfasis en ordenamiento territorial, EPG, Convenio UPTC-IGAC, Bogotá.
} 


\section{Introducción}

Al culminar la fase académica de esta Maestría que constituye el nivel más avanzado del Programa de Estudios de Posgrado en Geografía (EPG), con el presente trabajo de investigación en la línea de Geopolítica se pretende contribuir a la solución del grave problema que afecta actualmente a nuestro país por el conflicto de intereses que suscitó la llamada zona de distensión del Caguán, en relación con el proceso de paz que adelantó el Gobierno Nacional con fuerzas insurgentes. Se considera que el estudio de tan delicado tema adquiere marcada importancia por cuanto tiene estrecha relación con asuntos propios de la Geografía y además, se orienta a la atención de cuarenta millones de habitantes, quienes soportan toda clase de adversidades por el conflicto interno que durante casi cincuenta años ha afectado a Colombia y que hoy continúa vigente, cada vez con mayor crueldad.

Es preciso reconocer que la zona de distensión fue el resultado de un proceso de empoderamiento durante el conflicto como consecuencia de un plan estratégico de largo alcance por parte de la guerrilla. Lo sucedido en el territorio despejado demuestra que lo que se negociaba allí, precisamente, era el poder y no la ley. Es apenas justo que los colombianos sepan de una vez por todas, si estaban perdiendo espacio, porque una pérdida de espacio representa una pérdida de futuro. Cuando más espacio perdemos, menos somos.
Recuperar espacio perdido es también recuperar tiempo, es incrementar el potencial de la voluntad nacional. Esa recuperación no se puede dar contra un genérico "los otros", sino contra un específico, "el otro". La recuperación del espacio es la realización en la historia de un trabajo nacional liberador (Ceresole, 1991).

El Presidente de la República, Andrés Pastrana Arango, durante su campaña para llegar al Palacio de Nariño prometió a los colombianos solucionar el problema de la violencia, activando un proceso de paz con las guerrillas de las FARC (Fuerzas Armadas Revolucionarias de Colombia, según la propia organización), con el fin de brindar a los ciudadanos la tranquilidad y seguridad para alcanzar una sana convivencia. Una de las primeras acciones del Gobierno para iniciar su cometido, fue la de reunirse con el jefe guerrillero Manuel Marulanda Vélez y anunciar públicamente la activación de una zona de distensión, que serviría para realizar las conversaciones y coordinar todos los aspectos relacionados con un futuro proceso de paz.

En el sur-oriente del país y por exigencia de las FARC, se seleccionó un área de $42.139 \mathrm{~km}^{2}$ que incluyó cinco municipios (San Vicente del Caguán, La Macarena, Vista Hermosa, La Uribe y Mesetas) y se dijo que sería un "laboratorio de paz" (Ricardo, 1998); fue necesario despejar este territorio de fuerza pública y paulatina- 
mente por el accionar de los grupos rebeldes, también las autoridades legítimamente constituidas, tuvieron que evacuar la zona, en algunos casos con el agravante de amenazas de muerte. Se activó una Policía Cívica, como experimento inicial para mantener la seguridad y tranquilidad de los pobladores, mas no tardó mucho tiempo en generarse toda clase de conflictos porque en la práctica, la única ley imperante en la región era la de las armas, impuesta por el grupo insurgente de las FARC (figura No. 1).

Durante el desarrollo de la presente investigación se tuvieron como fundamento los hechos registrados por los diferentes medios de comunicación, por actores reales del conflicto, por autoridades suplantadas, por familiares de desaparecidos y asesinados y por diferentes entidades del orden nacional e internacional, que denunciaron los atropellos que en la zona de distensión se cometieron. Como el territorio despejado, teóricamente fue el escenario del proceso de paz (Pastrana, 1998), puesto que en él se llevaron a cabo las conversaciones, durante el desarrollo de esta investigación y en forma simultánea, fue posible observar los hechos reales que allí sucedieron y sus efectos geopolíticos.

Surgió la preocupación del investigador por explorar cómo desde el punto de vista geográfico la zona de distensión tuvo estrecha relación con los intereses políticos del Estado, por un lado, y por otro, de las fuerzas insur- gentes. Bien sabido es que uno de los elementos más importantes que conforman el Estado, es el territorio y que es en éste en donde la población realiza absolutamente todas sus actividades (Palacios, 1965). Así, pues, a partir de estos dos conceptos es posible desarrollar toda una teoría sobre las bondades o perjuicios actuales y futuros de la zona despejada.

Valió la pena explorar el proceso de definición espacial del poder de las FARC en Colombia. Ese fue el hecho geopolítico más importante de la zona de distensión porque surgió como condición de la negociación. Ahora bien, ¿por qué se busca una solución negociada al conflicto? Hay que aceptar que cuando dos bandos enfrentados no logran su objetivo violento, se plantea una negociación para dirimir ese conflicto y por lo tanto, lo que resulta no es la paz verdadera sino un simple periodo de tregua. "En efecto, cuando después del necesario reposo uno de los adversarios se cree en posesión de fuerzas que puedan permitirle mejorar la situación establecida por la tregua, vuelve a encenderse la lucha" (Carnelutti, 1994:13). Paralelamente se hicieron gestiones para adelantar el mismo proceso de paz con el grupo rebelde ELN (Ejército de Liberación Nacional, según sus fundadores). Esta intención generó un grave conflicto social porque los pobladores de la región seleccionada en el sur de Bolívar argumentaron que no deseaban vivir los "horrores y abusos que han padecido los habitantes de la zona 
de distensión del Caguán"; sin embargo, esta idea no ha sido descartada a la fecha.

En las diferentes etapas de elaboración de este trabajo se insistió en la exploración de nuevos elementos geopolíticos y en la explicación de la estrecha relación entre la Geografía y el poder, tomando como caso ilustrativo la zona despejada, conceptuando de manera clara para que en el futuro la toma de decisiones al respecto del uso del territorio de la Nación, se realice con pleno conocimiento de causa de las implicaciones geopolíticas. De esta manera, el estudio adquiere significado relevante para la Geografía, ciencia clave en el tema investigado y que presuntamente ha sido desdeñada por quienes desde el Estado, han convenido ciertos arreglos, sin tener en cuenta los aspectos científi$\cos$ y naturales y sus implicaciones en tales decisiones.

Algunos especialistas entre quienes figuran estadistas, politólogos, sociólogos, periodistas, militares activos y retirados, cuyos conceptos se incluyen en esta tesis, expresaron su temor por una posible balcanización del territorio nacional, que implicaría una situación similar a la ocurrida en la península de los Balcanes en la que el espacio comprendido entre antiguos imperios, ha sido reestructurado sucesivamente a lo largo del siglo $\mathrm{XX}$, en una serie de pequeñas naciones, entre las que se destacó durante algún tiempo la Federación de Yugoslavia. Allí todos los Estados se encuentran inmersos en querellas étnicas y territoriales, en un difícil equilibrio entre minorías y naciones soberanas. Sucesivas guerras en la década de 1990 en esta zona han venido a trastornar la compleja situación política heredada (López, 1999). Es conveniente, sin embargo, aclarar que el conflicto colombiano no partió de las causas que dieron origen al conflicto de los Balcanes.

El caso de la zona de distensión fue álgido y de alcance nacional e internacional, porque comprometió al Estado colombiano, como contraparte de un "tratado" que hoy algunos críticos consideran inconstitucional, a la sociedad civil, que se quejó de no haber sido consultada mediante un referéndum, y a la comunidad internacional que se manifestó con vehemencia por los desmanes y atropellos sucedidos en la zona de distensión del Caguán y denunciados públicamente (Beers, 2001).

Por ser un tema relativamente nuevo en el ámbito académico, existieron varias limitaciones, entre otras, la escasez de material bibliográfico, el difícil acceso a las informaciones de tipo judicial, el temor a la denuncia de hechos concretos, la crisis económica que impide el apoyo a la investigación, limitaciones estas que fueron superadas con el afán científico y la responsabilidad académica de quien se propuso desarrollar un trabajo serio y prospectivo. Por tratarse de un hecho hasta ahora no estudiado con rigor a

10 José Luis Cadena Montenegro 
nivel de maestría, se pretende sembrar la inquietud en las redes de investigación e investigadores independientes para que sea la sociedad científica la que también coadyuve, con fundamentos racionales, en la solución de un grave problema que subsiste como endémico, tortuoso e indefinido y que a la luz de la realidad, se convirtió para el actual gobierno en el factor más relevante de ingobernabilidad y para la ciudadanía, en una gran desilusión al confirmar que "la libertad sin una opción real para ejercerla es un regalo del diablo" (Chomski, 1999: 31).

Este trabajo está dirigido a los gobernantes actuales y futuros, a los responsables de elaborar las políticas de defensa y seguridad nacional, a los políticos, a los militares, a los universitarios que se preocupan por su país y a los violentos que han sembrado de cruces el territorio nacional, impidiendo el desarrollo y el mejoramiento de la calidad de vida de los colombianos.

En los ámbitos nacional e internacional funciona lo que se denomina sistema geopolítico, que no es otra cosa que el territorio o estructura espacial donde se plantean las interacciones de proximidad entre Estados contiguos (López, 1999). Pero a nivel regional y local, también es posible hablar en términos geopolíticos para resolver diferendos que se originan en el territorio. Sin embargo, lo que hoy se evidencia a nivel estatal en Colombia, es una indiferencia marcada con las políticas territoriales; no de otra manera se entendería el hecho de conceder extensos territorios a grupos asociados bajo cualquier pretexto. Por política territorial se entiende el conjunto de planteamientos estratégicos a mediano y largo plazos y de actuaciones dirigidas a intervenir sobre el territorio a fin de que asuma las formas adecuadas a los intereses que controlan el poder político (López, 1999).

\section{Contenido de la investigación}

El trabajo consta de cinco capítulos en los cuales se espacializó la información obtenida y los resultados de la investigación en forma clara y sencilla, de tal manera que el lector no tenga que recurrir a fuentes especializadas para comprender los temas tratados. El capítulo primero explica la metodología empleada para el desarrollo de la investigación, previo planteamiento del problema y propone el análisis de unas variables que se consideran sobresalientes. A partir del segundo capítulo o marco teórico, se realiza un recorrido histórico de la Geopolítica general para luego particularizarla en relación con el problema de investigación. Las teorías geopolíticas, la clasificación de la Geopolítica, su relación con otras ciencias y la utilización de la Geografía como un arma para la guerra son elementos teóricos que permitieron al autor encontrar explicación al fenómeno colombiano.

El capítulo tercero explica la presencia de las FARC en diferentes zonas 
del territorio nacional, analizando las variables escogidas y sus implicaciones en el proceso de paz que se adelantaba y que fracasó, del cual pasó a ser pieza fundamental la zona de distensión. El capítulo cuarto contiene el análisis específico sobre la Geoestrategia como herramienta de las FARC para continuar en su objetivo de la toma del poder; explica también cómo y por qué el Estado colombiano perdió soberanía en el territorio cedido a las fuerzas irregulares y también presenta el panorama sobre los nexos directos entre las FARC y el narcotráfico como estrategia de financiación del conflicto armado (Villamarín, 1996). También plantea un debate a partir de hechos concretos que sucedieron durante los tres años y medio del experimento como condición para iniciar un proceso de paz. Las conclusiones y recomendaciones del trabajo, forman parte del capítulo quinto y en ellas aparece la síntesis de la investigación, mostrando en forma objetiva y a la luz de los hechos estudiados las causas, los efectos y los posibles escenarios futuros en caso de que se hubiera prolongado el fenómeno de la zona de distensión.

\section{Resultados de la investigación}

La existencia de la zona de distensión generó una crisis de gobernabilidad en Colombia durante tres años y medio; esa crisis no fue el resultado coyuntural de fenómenos aislados que afectaron el comportamiento humano y que trascendieron el ámbito institucional.
Fue la sumatoria de desórdenes, malos manejos y decadencia de los valores sociales, generalmente catalizados por inexistencia de políticas y sobre todo, por ambiciones de poder, por engaños, por negociaciones ilusas y por la prepotencia de quienes supuestamente iniciaron una negociación de paz (Ceresole, 1991).

Las conclusiones de esta tesis se constituyen en respuestas al problema de investigación y en tal virtud, se refieren, no solamente al origen, a las causas, sino también a los efectos, a lo que sucedió y a lo que puede suceder en el ámbito geopolítico de Colombia, a partir de la que se llamó zona de distensión del Caguán. Como resultado relevante de la investigación, es necesario afirmar:

1. Que el crecimiento y el dominio territorial de las FARC fueron actividades planeadas estratégicamente como asuntos fundamentales de una campaña político-militar de largo alcance, para llegar al poder mediante la combinación de todas las formas de lucha. No ha sido casual la presencia guerrillera en diferentes lugares del territorio nacional, afectados por las seis variables seleccionadas para este trabajo (Tzu, citado por Wu Sun, 1997).

2. Que los distintos gobiernos elegidos en Colombia desde la década de los 60, hasta nuestros días, se han equivocado en el tratamiento al problema de la violencia armada, pretendiendo solamente manejarlo como una situa-

12 José Luis Cadena Montenegro 
ción de desorden público, dejando de lado las soluciones socioeconómicas que han servido de bandera a los rebeldes para mantener e incrementar su accionar en contra de la institucionalidad inicialmente, y de la población civil en esta época.

3. Que la ubicación de focos guerrilleros en sitios favorables geográficamente muestra a las claras que la iniciativa la han tenido históricamente las FARC, obligando al Estado a realizar operaciones militares orientadas a eliminar físicamente a los rebeldes, pero no a recuperar territorios y mucho menos a ejercer el dominio territorial. En pocas palabras, el Estado no se ha interesado por la Geoestrategia y pareciera que tampoco se ha dado cuenta que las FARC históricamente, si la han utilizado desde Marquetalia al Caguán (Cadena, 1999).

4. Que el poder coercitivo del Estado colombiano representado por sus Fuerzas Armadas (Ejército, Marina, Fuerza Aérea, Policía Nacional) ha dado respuestas coyunturales a las acciones delictivas de la guerrilla de las FARC, pero hasta la fecha no ha sido posible la solución del conflicto por la vía armada. Durante décadas, el Estado se sintió protegido por su brazo armado y no tomó en serio su participación con miras a erradicar definitivamente las causas del levantamiento subversivo. Solamente a partir de la década de los 90 , en la cual los grupos armados ilegales señalaron a las élites políticas como objetivo mi- litar, los gobiernos de turno entendieron que lo que ha existido en Colombia es un conflicto de baja intensidad, que amenaza no únicamente al Estado, sino también a la población civil (Marulanda, 1990).

5. Que el uso de sitios específicos del territorio nacional por parte de las FARC para practicar la guerra de guerrillas, y de las Fuerzas Armadas para su lucha contraguerrillera, confirma que ha sido evidente a lo largo del conflicto el ejercicio de la Geoestrategia, para el cumplimiento de los objetivos políticos y militares. No en vano las FARC, generaron durante décadas, su propio espacio en un territorio que terminó denominándose zona de distensión y que fue exigido como condición esencial para iniciar un proceso de paz durante el gobierno del Presidente Andrés Pastrana. Lo que se observa a través de la investigación es que las FARC, sistemáticamente lograron el dominio territorial de esa extensa región que abarca $42.139 \mathrm{~km}^{2}$, mientras el Estado se despreocupó por la misma, generando solamente acciones militares episódicas, que nunca fueron complementadas con planes socioeconómicos para ejercer su poder, amenazado y disputado por las armas de la subversión (Small, 1997). No debemos olvidar que el dominio es una facultad inherente a la soberanía (García, 1983). Durante casi 50 años la que a partir del 20 de febrero de 2002 dejó de llamarse zona de distensión, se mantuvo bajo el aparente dominio 
estatal pero el poder real lo ejercieron las FARC y es por esa razón, que fue allí, y no en otra región donde los rebeldes exigieron reunirse a partir del mes de noviembre de 1998.

6. Lo que en esta tesis se denomina territorialización del poder por parte de la guerrilla de las FARC, tiene estricta relación con la presencia del grupo armado en sitios específicos de la geografía nacional y con el ejercicio del poder, por coacción o por convicción de sus habitantes (James, 1993). Las seis variables estudiadas y denominadas zonas periféricas, de colonización, de precaria presencia estatal, de cultivos ilícitos, de explotación petrolera, y suburbanas, (figuras 2, 3, 4, 5) se constituyeron en los objetivos geoestratégicos de las FARC, para plantearle al Estado y a la población civil, la guerra irregular que aún subsiste y que actualmente ha tomado como alternativa coyuntural, la más cruel de las variantes: el terrorismo (Santos, 2001). Lo más importante de esas seis variables, sin duda alguna, es el aspecto geográfico, apropiado para practicar la guerra de guerrillas y mantenerse en actividad a pesar de las acciones contrainsurgentes por parte del Estado; en orden de importancia el segundo aspecto es el económico a partir de las mismas seis variables, porque ha permitido a los rebeldes, desde la subsistencia elemental, hasta el financiamiento de una guerra cruel que exige elevados gastos para mantener el aparato bélico irregular (Perpiñá, 1993). Desde los tiempos de la extorsión y las vacunas a campesinos y terratenientes hasta el monopolio en el proceso del narcotráfico, las guerrillas de las FARC han acumulado grandes sumas de dinero que le han permitido crecer cuantitativamente y ocupar nuevos territorios dependiendo de sus propias necesidades. Lo más grave es que 50 años después existan en el territorio nacional, zonas donde el Estado no ejerce su dominio y menos el poder real (figuras 6, 7, 9). Es en esas zonas donde las guerrillas imponen su voluntad y ejercen verdaderamente el monopolio de la fuerza (Cadena, 1999).

7. El narcotráfico es un aspecto de vital importancia para la subsistencia del conflicto armado porque ha sido en los últimos años una de las principales estrategias de las FARC, para conseguir los recursos que demanda la guerra (Villamarín, 1996). Hoy se conoce claramente que durante los tres años y medio de duración de la zona de distensión, los cultivos de coca y amapola crecieron en la región en forma logarítmica y ha quedado al descubierto que las FARC manejaban allí todo el proceso, desde la siembra hasta la exportación. Esta actividad delictiva formó parte de la geoestrategia guerrillera en la zona del Caguán y es posible afirmar que desde tiempo atrás, se realizaba a escalas menores $\mathrm{y}$ en tal virtud, han empleado corredores de movilidad como los que se muestran en la figura 10 (Castillo, 1987). Pero no ha sido solamente en esa región del país donde las FARC han tenido el monopolio del narcotráfico, puesto que existen otras

14 José Luis Cadena Montenegro 
zonas de igual o mayor importancia, que están siendo disputadas también por los paramilitares bajo el pretexto de la necesidad de obtener recursos para financiar sus actividades contraguerrilleras (figuras 11, 12). La guerra es tal vez la actividad más costosa y en tal virtud requiere de inmensos recursos para lograr una definición en el campo militar y en Colombia ha sido y sigue siendo el narcotráfico, uno de los principales puntales utilizados por parte de los grupos armados por fuera de la ley.

8. Durante la investigación fue posible determinar que entre 1964 y 1980, las FARC iniciaron su construcción territorial a partir de las zonas periféricas, zonas de colonización y zonas de precaria presencia estatal, sumando en total diez grupos de diferente denominación (cuadrillas, guerrillas, frentes). Se trataba de organizar el aparato rebelde fuera del alcance de las tropas estatales, logrando la subsistencia económica en forma precaria porque los recursos en esas zonas no eran abundantes. Entre 1981 y 1989 la territorialización del poder se extiende a las zonas de cultivos ilícitos y de explotación petrolera, apareciendo en la geografía nacional un total de 33 grupos que se suman a los diez ya existentes. El crecimiento del aparato rebelde requirió de mayores recursos $y$ en tal virtud las FARC incrementan su accionar delictivo, especialmente relacionado con el narcotráfico. Entre 1990 y 1995 las FARC accesan a zonas suburbanas y en ese lapso apa- rece un total de 18 grupos nuevos en diferentes sitios del país. Se trataba de mostrar gran poder de fuego y capacidades militares con el fin de obtener del Estado el tratamiento conveniente para sacar ventajas en una posible negociación de paz. Para 1996 los 61 grupos armados de las FARC tenían influencia en el poder local de por lo menos 600 municipios de los 1.072 existentes. Además de las acciones militares, las FARC ejercían en esta época gran influencia en las decisiones políticas en un buen número de entidades estatales a nivel local y regional (Echandía, 1998).

9. No deja de sorprender que en el año 2001 la mayor parte del dispositivo de las FARC esté ubicado aún en zonas periféricas con un total de 66 frentes, dos bloques móviles, 14 columnas, 19 compañías y seis unidades de diferente denominación, lo que demuestra que el Estado colombiano no ha sido capaz ni política ni militarmente, de contener el crecimiento de las FARC y menos de erradicarlas de los sitios geográficos tradicionalmente colonizados por ellas para ejercer el poder real (Cadena, 1999).

10.La zona de distensión se terminó legalmente el 20 de febrero del 2002 porque el Presidente Andrés Pastrana ordenó a las Fuerzas Militares iniciar operaciones ofensivas contra las FARC, al romperse definitivamente las conversaciones del proceso de paz, pero en la realidad éstas no han salido del territorio y difícilmente lo harán 
porque su presencia allí y el poder que han ejercido y ejercen tanto en la región del Caguán como en los cinco municipios que formaron parte del territorio despejado, es el resultado de su construcción territorial desde 1964, fecha en que salieron de Marquetalia hacia el Meta, con el claro objetivo de llegar al poder sin que el tiempo sea el elemento determinante en sus planes. Es posible afirmar entonces que ha desaparecido por ahora la territorialidad legalizada por el gobierno de Andrés Pastrana pero se mantiene y quién sabe hasta cuándo la correspondiente a un grupo armado con poder de control (Santos, 1996).

11. Del análisis de la ocupación territorial de las FARC se concluye que cuando el Estado ha ejecutado presión mediante operaciones militares a gran escala en sitios específicos, la guerrilla de las FARC ha cambiado temporalmente de sede pero en forma cíclica y circular, vuelven a sus antiguos territorios a ejercer el poder real que el Estado ha perdido (Sanguín, 1981). El experimento de la zona de distensión sin duda alguna, le sirvió a las FARC para practicar su forma particular de gobernar en un territorio superior en extensión a varios países desarrollados (Salcedo, 1999). Cuando las Fuerzas Militares salgan de la antigua zona de distensión porque las FARC le plantean otro tipo de guerra que requiera de su presencia en diferentes lugares, la guerrilla volverá a practicar lo que ya sabe hacer. Será la triste realidad si el Estado colombiano no acepta sus errores históri- cos y se propone enmendarlos; el cómo hacerlo no es propósito de esta investigación y para ello están los políticos, los militares y todos los asociados del Estado colombiano.

12. Desde el punto de vista de la Geopolítica, la llamada zona de distensión impactó negativamente las relaciones económicas, políticas, sociales, sicológicas, culturales y ambientales a nivel nacional, por cuanto existió la presunción de la aparición de un nuevo estado dentro del territorio colombiano; el hecho más relevante al respecto fue la pérdida de soberanía por parte del Estado colombiano en razón al no cumplimiento de sus leyes en un espacio en el que temporalmente gobernaron las FARC. Al delimitar la zona para impedir el accionar militar de las tropas estatales, se crearon fronteras físicas y fronteras políticas que no debían ser sobrepasadas por los combatientes (López, 1999); esta obligación solo se aplicó durante el tiempo de existencia de la zona de distensión a las Fuerzas Militares estatales. En el ámbito internacional no fueron pocos los acontecimientos que causaron alarma en las fronteras de países vecinos; se sabe que las FARC traspasaron los límites territoriales de Ecuador, Perú, Brasil y Venezuela, cuando a partir de la zona de distensión, realizaron operaciones militares o de narcotráfico. En repetidas ocasiones la diplomacia colombiana se vio en apuros para dar explicaciones a sus homólogos de otras naciones.

16 José Luis Cadena Montenegro 
13. En relación con el proceso de paz que con tanta ilusión esperaban los colombianos, la zona de distensión del Caguán no produjo ningún resultado positivo; todo lo contrario, las guerrillas de las FARC se aferraron al territorio y ampliaron sus fronteras mediante operaciones militares continuas en contra de las tropas estatales y de la población civil. Las negociaciones se orientaron a imponer condiciones para el control territorial de manera tal que las FARC, no tuvieran obstáculo alguno para gobernar a su mane$\mathrm{ra}$, emitiendo sus propias leyes ( $\mathrm{Re}-$ yes \& Gómez, 1998). Por eso al culminar esta investigación, existen argumentos suficientes para afirmar que en la zona de distensión del Caguán durante tres años y medio, se alcanzó a gestar un Estado sin nación.

\section{El debate y la reflexión}

Se considera conveniente plantear un debate para profundizar hasta dónde el experimento de la zona de distensión ha impactado la Geopolítica nacional e internacional. Es una invitación a la reflexión, tomando hechos concretos que facilitan el proceso de análisis-síntesis y que a partir del momento están abiertos a la discusión:

Es posible que por primera vez se afirme que la operación Marquetalia no fue un éxito sino un fracaso, pero algunas personas le han hecho creer al país entero que en aquella oportunidad se cumplió la misión (Matta, 1999). Si eso hubiera sido cierto, en- tonces hoy no fuera posible hablar de la territorialización del poder por parte de la guerrilla de las FARC. Cuando las tropas que sostienen el Estado de Derecho no tienen la suficiente capacidad coercitiva, el imperio de la ley es desbordado poniendo en peligro la institucionalidad y por ende, la propia existencia de la nación (Ceresole, 1993). Pero lo que en este trabajo más interesa, es el aspecto geográfico y su influencia político-militar y en tal virtud, la primera verdad a tener en cuenta es, que fue en Marquetalia donde las guerrillas de las FARC establecieron su primer foco territorial y que la operación militar en su contra, las hizo cambiar de estrategia proyectándolas como guerrillas móviles y obligándolas a transitar otros territorios (Sánchez \& Peñaranda, 1991). En los últimos años las FARC buscaron acercarse a los centros de poder económico y político y mediante la táctica de desdoblamiento de sus unidades guerrilleras (Echandía, 1998), crearon otras con el fin de mostrar a nivel nacional e internacional que su crecimiento era indicativo de gran fuerza insurgente y por lo tanto, la toma del poder estaba cercana. "Una conclusión ligera llevaría a afirmar que la poca importancia dada al espacio en nuestro país también es responsable del escaso interés que se le concedió a la Geografía” (Delgado, 2001:24).

Existen sitios del territorio nacional donde las FARC no han podido copar el poder local; esta reflexión infiere que no es suficiente la ocupación o 
presencia territorial solamente, sino que además, es necesario construir espacios a través de las relaciones con el entorno y principalmente con los habitantes (Santos, 1996); de ahí su insistencia en no querer desprenderse de algunos territorios, o de intentar recuperarlos cuando han sido expulsados por las fuerzas estatales o por los paramilitares. Es posible que en la desactivada zona de distensión se haya presentado ese fenómeno y que si el Estado continúa de espaldas a la realidad, en el futuro cercano pueda consolidarse (González,1990). Se advierte que hasta la fecha el Estado no ha hecho verdadera presencia en zonas que históricamente han servido a las FARC para la realización de sus objetivos intermedios (Lacoste, 1977).

En el plano de la Geopolítica mundial no se puede negar que el control jerárquico del Estado ha retrocedido ante complejas pautas de negociación; las fronteras son penetrables y pierden su significado cuando actores no estatales pueden maniobrar sin límites a través del espacio (Perpiñá, 1973). El ejercicio del poder por parte del Estado ha dejado de tener un carácter de exclusividad para basarse en criterios alternativos de competencia. Pero eso no implica que ese Estado renuncie al dominio, a la soberanía y al control político sobre su propio territorio (López, 1999).

La que se denominó zona de distensión está ubicada en el centro geográficoestratégico, que no es otra cosa que la zona del país donde es factible articular en espacios y tiempos suficientes, el potencial ofensivo-defensivo de la propia fuerza en relación con la hipótesis de guerra formulada (Ceresole, 1991). Por esta razón las FARC construyeron vías carreteables que les proporcionaron facilidades para transportar armas, insumos para la elaboración de pasta de coca, droga procesada y terroristas para asaltar y destruir poblaciones indefensas. En geopolítica, los transportes son de vital importancia y por lo tanto en el planeamiento estratégico, ocupan un primer lugar (Chías, 2001). Lo que se observa es que en Colombia, el Estado se ha despreocupado por ese importante sector y la guerrilla ha explotado esa debilidad estatal a su favor. Es indudable, como se desprende del análisis de este proceso de territorialización del poder por parte de las FARC que han hecho un eficiente uso de la Geoestrategia a partir de la zona de distensión, para desarrollar sus planes tendientes a la toma del poder por la fuerza (Lacoste, 1977).

Teniendo claridad que el poder es la capacidad de dominar un espacio geográfico para movilizar y asignar recursos e información y para estructurar intencionadamente el campo de decisión y que el poder político, entonces, es la capacidad de dominio y resolución de los conflictos en un marco espacial, es imperativo afirmar que fueron las FARC las que ejercieron el poder real en la zona de distensión (López, 1999). Fueron ellas las que aplicaron dentro del territorio el

18 José Luis Cadena Montenegro 
poder militar, económico, político, judicial y sicológico; los continuos acontecimientos mediante los cuales se confirma que allí solamente se ejecutó lo que la guerrilla dispuso, así lo demuestran. Públicamente manifestaron que el gobierno llegó a un acuerdo con ellos y que lo que no estaba restringido por escrito, les era permitido (Briceño, 1998). Todo indica que las FARC si están convencidas que los grandes espacios son generadores de poder nacional.

El hecho de concebir la idea de que las relaciones de poder y la política existen en toda relación social, y no sólo en las instituciones del Estado y del gobierno, es importante (Painter, 1998). Lo que sucedió en la zona de distensión se refleja en todo el país afectando la nacionalidad y generando terror; así también las FARC generan espacios de poder. Sin embargo, dice Ramonet (1998:23) que "la supremacía militar no se traduce ya de forma automática en conquistas territoriales, que se convierten en imposibles de gestionar políticamente, demasiado costosas desde el punto de vista financiero y mediáticamente desastrosas". Tradicionalmente las conquistas territoriales se combinan con otros tipos de guerra entre los cuales vale la pena destacar la guerra sicológica, la guerra política y la que parece ser la nueva alternativa de las Farc, la guerra económica que persigue disminuir o eliminar los recursos del contrincante para diezmar su poder relativo de combate (Perpiñá, 1973).
Nadie diferente de las FARC conoció a ciencia cierta el funcionamiento al interior de la zona de distensión. Solamente por los organismos de inteligencia se supo de algunas actividades que allí se realizaron y que reñían totalmente con la concepción inicial de contar con un sitio tranquilo para conversar del proceso de paz. En tiempos de globalización fue la única parte del planeta donde existió un territorio inmenso, mayor en extensión a países desarrollados, en el que los ciudadanos nacionales y extranjeros no podían ingresar sin autorización de las FARC (Salcedo, 1999). Se sabe que existieron dentro de los 42.139 kilómetros cuadrados, lugares restringidos porque allí funcionaban campos de entrenamiento militar y otras instalaciones proyectadas para la guerra y no para la paz.

Desde el inicio de la zona de distensión en noviembre de 1998, ese territorio fue totalmente controlado por las FARC y en tal virtud, no existió ninguna intervención por parte del Estado, presentándose un inmenso vacío al respecto del ordenamiento territorial conforme a las leyes vigentes. Mientras en todos los municipios del País los planes obedecen a un proceso de participación democrática, en la zona de distensión nadie sabe a ciencia cierta cuál fue la metodología y qué papel jugó la sociedad civil si es que así se puede llamar a una comunidad que se encontraba bajo un régimen jurídico y político diferente al que impera en el resto del territorio colom- 
biano, porque allí no existieron los elementos básicos necesarios para integrarse a la nacionalidad (Massiris, 1998).

En los cinco municipios pertenecientes a la extinta zona de distensión, el Estado no operó durante tres años y medio y en tal virtud, el ordenamiento territorial que allí se dio fue impuesto por la guerrilla de las FARC, buscando únicamente el desarrollo de sus intereses. Al aceptar el gobierno el inicio de una negociación en medio del conflicto armado, justificó que las FARC continuaran combatiendo al Estado desde ese territorio, como centro de operaciones con el consecuente empleo geoestratégico (Lacoste, 1977). Ahora bien, al romperse el proceso de paz y terminarse la zona de distensión desde el punto de vista legal, los problemas relacionados con el ordenamiento territorial no se han resuelto; las FARC continuarán haciendo presencia en ese territorio y la situación seguramente será similar a la que se presentaba antes del mes de noviembre de 1998. Durante casi 50 años las FARC generaron su propio espacio en ésta y en otras zonas del país y por eso seguirán buscando su consolidación. El Estado debe aplicar eficientes políticas y estrategias si su deseo es mantener la integridad del territorio de la Nación (Cadena, 1999).

Es evidente que el control del orden público y del comportamiento de la ciudadanía en general, lo realizaron las FARC en la zona de distensión porque permanentemente instalaban retenes sobre las vías, cobraban peajes e impedían el tránsito de personas y vehículos en horarios por ellos impuestos, reteniendo pasajeros por sospecha de paramilitarismo. Se sabe plenamente que tuvieron injerencia en asuntos que iban desde problemas familiares hasta negocios de dinero y especialmente de tierras. Imponían castigos y penas graduadas desde la obligación de asear las plazas públicas hasta el destierro o el fusilamiento. El control de orden público que se ejerció en la zona de distensión refleja que al contrario de lo acontecido en otras épocas, los rebeldes requirieron de abundantes redes de comunicaciones, pues se trataba de dispersar a las fuerzas estatales mediante ataques sorpresivos a pequeñas poblaciones conectadas a las redes de transporte departamentales y nacionales. Dentro de ese mismo propósito, las FARC iniciaron una actividad terrorista a la que denominaron "pesca milagrosa" consistente en instalar retenes ilegales donde escogían a sus víctimas y las secuestraban para luego exigir grandes sumas de dinero por su liberación (Vargas, 2001).

Desde el inicio de la zona de distensión las FARC construyeron una infraestructura para albergar a 10.000 personas aproximadamente que incluía lo que llamaron Villa Colombia donde se realizaron las conversaciones con delegados del Gobierno. Pese a contar con todas las comodidades posibles en la zona, ninguna empresa de 
servicios públicos percibió dineros por el usufructo de los mismos. Las FARC operaron una inmensa red de comunicaciones inalámbrica empleando cientos de frecuencias del espectro radioeléctrico sin que cancelaran un sólo peso por ese concepto al Ministerio de Comunicaciones.

Nadie sabe exactamente a quién pertenecen las tierras en las cuales las FARC construyeron sus campamentos; sin embargo, hoy se conoce que desterraron a muchos propietarios de fincas y parcelas, en algunos casos después de obligarlos a firmar la entrega de sus bienes. Guerrilleros desertores informaron que los planes incluían el acaparamiento de todas las fincas de esa zona para organizar un nuevo estado donde las FARC iniciarán la "nueva Colombia". Allí se estaba presentando el fenómeno de la difusión espacial que es el proceso por el que el comportamiento o las características de un territorio, cambian como consecuencia de lo ocurrido antes en otro lugar. La difusión espacial es la propagación de un fenómeno en el espacio y en el tiempo, desde unos orígenes limitados (Méndez, 1997). Marquetalia, Río Chiquito, El Pato y El Guayabero pudieron servir de paradigma para una nueva república independiente en el Caguán.

Ante la ausencia de autoridades legítimas que representaran el Estado de Derecho, las FARC asumieron la administración de los espacios terrestre, fluvial y aéreo, so pretexto de proporcionarse su propia seguridad. Lo que queda claro es que al suplantar al Estado, se cometió toda clase de violaciones a los derechos fundamentales de los ciudadanos que por sus propias razones continuaron viviendo en la zona y no pudieron abandonarla como sí ocurrió con una gran cantidad de colombianos que pasaron a formar parte de ese grupo de excluidos, al que olímpicamente llamamos desplazados y por los que nadie se preocupa. Se volvieron cotidianos los llamados retenes ilegales instalados por las FARC para realizar las ya conocidas "pescas milagrosas" que no son sino vulgares secuestros de gente inocente (Gómez, 2000).

Al terminarse la zona de distensión es necesario concretar si su activación facilitó o no el avance en las conversaciones de paz. Se creyó inicialmente, que era para conversar y para adelantar el proceso que tanto anhelamos los colombianos para poder vivir en paz. Sin embargo, hoy el desencanto es general, pues la zona sólo sirvió como campo de entrenamiento de terroristas, campo de concentración de secuestrados, laboratorio para producción de coca, asesinato de colombianos y extranjeros, expulsión de autoridades legítimas e infinidad de delitos atroces. Sirvió la zona para que las FARC adoptaran una actitud soberbia y los colombianos perdieran la esperanza en un proceso de paz. Desde el punto de vista político, sirvió para que la mayoría de los colombianos entendieran que las FARC no han estado ni están interesadas en la solu- 
ción negociada del conflicto y que solo la guerra es su opción. Ha sido la derrota política más estruendosa para la guerrilla, paradójicamente, gestada por sus propias acciones. Desde el punto de vista militar, sirvió para que las FARC se fortalecieran y replantearan sus operaciones con miras a la toma del poder por la vía armada, causando mucho daño a la población civil y a la economía nacional, quedando claro que las FARC sí han empleado la Geografía como un arma para la guerra (Lacoste, 1977).

\section{Prospectiva ante el desinterés por el territorio}

Los escenarios de la Geopolítica han cambiado. La tecnología, la desideologización, consecuente al fin de la llamada guerra fría, implican una transformación del fenómeno de la guerra también. La tendencia a la internacionalización de todos los conflictos en la globalización reinante es irreversible. No sería extraña una intervención extranjera en nuestro país para erradicar el problema que hoy aqueja a los colombianos ante la indolencia de los gobernantes del pasado y del presente. Lo más grave sería que los próximos gobiernos continuaran disponiendo irresponsablemente del territorio para otras zonas de distensión so pretexto de alcanzar la paz, poniendo a la Nación en grave riesgo de desintegración y de pérdida de los valores nacionales.

Que el gobierno actual y los futuros sean o no conscientes de lo que está sucediendo, que la comunidad internacional esté reaccionando; que el país se siga desintegrando, que los colombianos actuemos a tiempo serán asuntos de los que sólo tendrán noticia las futuras generaciones; aquellas que nos juzgarán por haber permitido que sigan viviendo como esclavos del desorden, del crimen, de la violencia y sobre todo, de la negligencia estatal. A simple vista, las FARC durante sus fases de crecimiento, han aplicado las teorías de Mahan y Mackinder, es decir, se observa la práctica de las más elementales y antiguas teorías geopolíticas para la conquista y expansión territorial, solo que en este caso estamos hablando de una geopolítica dentro de las fronteras territoriales de la Nación.

La defensa y la seguridad nacional son dos elementos importantes del poder, sujetas a la acción política por tratarse de herramientas fundamentales para mantener el monopolio de la fuerza, proporcionando así a toda una nación las posibilidades para su desarrollo $(\mathrm{Ca}-$ dena, 1999). Los bienes públicos puros y meritorios pertenecen a todos los ciudadanos sin excepción. La defensa y la seguridad forman parte de esos bienes y es precisamente el Estado el responsable de producirlos. Cuando un Estado se torna ineficiente e ineficaz, existe grave riesgo de anarquía.

La Constitución Política de Colombia de 1991, Título I, de los Principios Fundamentales, Artículo 2, contempla entre los fines esenciales del Estado:

22 José Luis Cadena Montenegro 
"defender la independencia nacional, mantener la integridad territorial y asegurar la convivencia pacífica y la vigencia de un orden justo". Este fin, con base en los límites internacionales trazados y reconocidos legalmente, así como en las normas dispuestas por el Estado, de estricto cumplimiento por parte de los ciudadanos. En Colombia se presentan amenazas contra la seguridad externa e interna; hay naciones que reclaman espacios marítimos y territoriales que ancestralmente han sido de Colombia y otras que ejercen presiones en la conducción de sus asuntos internos, apoyados en formidable poder coercitivo. El Estado tiene la obligación de custodiar ambos frentes por mandato de la Constitución Nacional, empleando los recursos de la diplomacia y el Derecho Internacional en el externo, con respaldo adecuado de poder militar y los medios políticos, económicos y de fuerza pública que la ley permite en lo interno (Valencia, 1997).

Si se hubiera persistido en la determinación de extender las prórrogas para el funcionamiento de la zona de distensión, las FARC, en el mediano plazo habrían podido imponer su voluntad, argumentando que como era en ese territorio donde ellas habían generado su propio espacio, éste les pertenecía. En ese momento se habría iniciado un fenómeno similar al de la balcanización, explicado en la introducción de esta tesis, porque otros grupos armados de izquierda y de derecha hubieran pretextado la misma situación para exigir otros territorios. Pero también pudo suceder que a cambio de la tan anhelada paz, las FARC propusieran la federalización de Colombia como una de sus exigencias y se aprovechara ese territorio como inicio del experimento. El Estado colombiano en adelante, debe ejercer el poder como recurso para alcanzar las metas de un gobierno y en especial, el poder público que es el que permite organizar soberanamente a una sociedad determinada. Hay que recordar que el poder significa legitimidad y autoridad con el propósito de gobernar y/o dirigir grupos sociales.

Teniendo en cuenta que la desactivada zona de distensión del Caguán es un extenso territorio con características geoestratégicas, el Estado colombiano debe recuperarlo prioritariamente e integrarlo a la nacionalidad mediante planes de desarrollo que permitan su sostenibilidad y que garanticen a sus habitantes hacer uso pleno de todos sus derechos y gozar de las comodidades que como seres humanos deberían tener. Las estrategias para el cumplimiento de este gran objetivo nacional deben tener muy en cuenta los aspectos económicos, políticos, sociales, militares y sicológicos para evitar que el fenómeno se repita cíclicamente. Cuando una sociedad no puede controlar su espacio, es que está en vía de desaparición o en decadencia continua, lo que es lo mismo. Todo espacio que no se domina es siempre dominado por otros (Ceresole, 1991). 


\section{Bibliografía}

AGUILAR VILlanUEVA, Luis F. El Estudio de las Políticas Públicas. México. Ed. Miguel Ángel Porrúa. 1992. 189 p.

AGUILERA PERALTA, Gabriel. Seguridad, Función Militar y Democracia. Editorial Impreofset. Guatemala. 1994. 385 p.

ANGARITA FIGUEREDO, Luis Hernando. "El Derecho Internacional Humanitario y el Conflicto Armado”. En Revista Policía Nacional. Colombia. Mayo-Agosto. 1995 No. 225.

ARDILA MALAVER, Aura Cecilia y RODRIGUEZ VALBUENA, Danilo F. Proceso de urbanización en el Piedemonte Llanero. Caso Tame Arauca. En: Memorias XVI Congreso Colombiano de Geografía. Santiago de Cali, 17 al 20 de agosto de 2000.

ARISTÓTELES. La Política. Medellín Colombia: Bolsilibros Bedout. Volumen 190. Abril 1992.

ATEHORTUA CRUZ, Adolfo y VELEZ RAMÍREZ, Humberto. Estado y Fuerzas Armadas en Colombia. Tercer Mundo Editores. Santafé de Bogotá D.C. 1994. 244 p.

AVEllanedA C., Alfonso. Petróleo Colonización y Medio Ambiente en Colombia. De la Tora a Cusiana. Ecoe Ediciones. ISBN: 958-648-169-7. Santafé de Bogotá, D.C. Agosto de 1998. 184 p.

BAGLEY, Bruce M. Et all. Colombia Internacional. Edición Especial. Centro de Estudios Internacionales de la Universidad de Los Andes. La "Crisis" colombiana: Causas y repercusiones externas e internas. Editor CEI. ISSN:0121-5612. Bogotá, D.C. 2001.

BEERS, Rand. Entrevista con Jineth Bedoya Lima. El Espectador, Bogotá: 18 de marzo, 2001.

BERMÚDEZ ROSSI, Gonzalo. El Poder Militar en Colombia. Desde la Colonia hasta el Frente Nacional. Segunda Edición. Bogotá. Ediciones Expresión, 1985. 211 p.

BERRIO MUÑOZ, Gustavo. Algo más sobre nuestra situación internacional. En: Revista Boletín de la Sociedad Geográfica de Colombia. Volumen 36 No.118. Bogotá 1983.

BORJA, Miguel. El Ordenamiento Territorial como una de las variables para la organización de un nuevo acuerdo social y político en Colombia. En: Memorias XVI Congreso Colombiano de Geografía. Santiago de Cali. Agosto 2000.

24 José Luis Cadena Montenegro 
CADENA MONTENEGRO, José Luis. Evaluación de la Eficiencia y Eficacia del Ejército de Colombia. Tesis de Grado para optar al título de Magister en Ciencia Política. Universidad de Los Andes. Bogotá Colombia. Septiembre 1999.

. La Planeación Urbana frente a los Riesgos Sísmicos en Santafé de Bogotá, D.C.. Tesis de Grado para optar al título de Magister en Planeación Socioeconómica. Universidad Santo Tomás. Bogotá Colombia. Diciembre 1999.

CARDONA LONDOÑO, Antonio- CHOUE, Young Seek. La Ciudadanía Mundial. Editorial Planeta. Primera Edición. Santafé de Bogotá, D.C., agosto 1993.

CARNELUTTI, Francesco. Cómo nace el Derecho. Monografías jurídicas No.54. Traducción de Santiago Sentis Melendo y Marino Ayerra Redín. Segunda Edición. Santafé de Bogotá. Editorial Temis S. A. 1994.

CARUSO, Douglas and PALM, Risa. Social Space and Social Place. The Professional Geographer. Forum and Journal of The Association of American Geographers. Volume XXV. Number 3. Donald J. Patton, Editor. Florida State University. August, 1973.

CASTELLS, Manuel. La Cuestión Urbana. Bogotá, D.C. Colombia: Siglo Veintiuno Editores. 1974.

CASTILLO, Fabio. Los jinetes de la cocaina. Editorial Documentos Periodísticos. ISBN. 958-951550-9. Bogotá, noviembre 1987.

CASTRO ESCOBAR, Pablo. IBARRA, Aurelio. Abogados. Fortalecimiento de las Administraciones Nacionales para la Integración - El caso Colombiano - Informe Final. CEFIR. 1993. 28 p.

CEFIR. Conferencia de Apertura. La Integración Regional de América Latina y Europa: Objetivos Estratégicos y Refuerzo de las Capacidades de Respuesta. Montevideo 9-12 marzo/93. 66 p.

CEFIR. Curso de Formación. La Integración Fronteriza en el Grupo Andino y en la Unión Europea: Experiencias, opciones y estrategias. Cartagena de Indias. 26 de septiembre. 1 de octubre 1994. Documento Final. 128 p.

CEPAL (Consejo de Economía y Política para América Latina). Desarrollo reciente de los Procesos de Integración en América Latina y el Caribe. Distribución RESTRINGIDA (5 de mayo de 1994). 82 p.

CERESOLE, Norberto. Política Nacional y Proyecto de País. En un mundo apolar. El bloque editorial. Buenos Aires 1993. 362 p.

. Tecnología Militar y Estrategia Nacional - Política y Economía de la Defensa. Buenos Aires. Argentina. Editorial Pleamar. 1991. 223 p.

CHIAS BECERRIL, Luis. Las externalidades como problema emergente del sistema de transporte metropolitano. Conferencia para el Seminario del EPG UPTC IGAG. México D.F.

CHOMSKI, Noam. La nueva estrategia militar de Estados Unidos. En: Geopolítica del Caos. Le Monde Diplomatique. Edición Española. Barcelona: Editorial Debate. 1999.

CONVERS PINZON, Rafael. Proyecto de Desarrollo para los Territorios Nacionales. En: Revista Boletín de la Sociedad Geográfica de Colombia (Academia de Ciencias Geográficas). Volumen 30 No.108. Bogotá Colombia, 1976. 
CORPES. La Orinoquía Colombiana. Visión Monográfica. Segunda Edición. Santafé de Bogotá D.C: 1996-2000.

CROMOS. Revista No. 4046. Santafé de Bogotá, D. C. 14 de agosto 1995.

DELGADO MAHECHA, Ovidio. Discurso sobre el espacio en la Geografía contemporánea. En: Revista Semestre Geográfico. Publicación arbitrada de la Asociación Colombiana de Geógrafos-ACOGE. Volúmen 1-No.1. Bogotá, D. C. ISSN-1657-3234.

ECHANDIA CASTILLA, Camilo. El conflicto armado y las manifestaciones de violencia en las regiones de Colombia. Presidencia de la República, Oficina del Alto Comisionado para la Paz. Observatorio de la Violencia. Santafé de Bogotá, D. C. 1998.

EL ESPECTADOR. Revive polémica por área de distensión. "El despeje es discrecional del Presidente". Domingo 1o. de octubre de 2000.

EL TIEMPO. Choque por despeje indefinido. "Proceso de Paz se puede diluir": Lloreda. Martes 25 de mayo de 1999.

EL TIEMPO. El cumpleaños del despeje. Domingo 7 de noviembre de 1999.

EL TIEMPO. Noticias en breve. Santafé de Bogotá D. C. 1o. de octubre de 1998.

FLOREZ Antonio, WILLIAMS MONTOYA Jhon, DELGADO MAHECHA Ovidio. Lecturas en Geografía - Traducciones. Universidad Nacional de Colombia, Facultad de Ciencias Humanas, Departamento de Geografía.

FRANCO, Roberto. Historia de Orocué. Bogotá. D. C. Kelt Colombia S.A. Ecopetrol. 1997.

FUNDAGRO. La sostenibilidad en el sector agropecuario. En: cuadernos de desarrollo agrícola. Vol. 1, 2 y 3, Santafé de Bogotá, D. C. marzo 1996.

GARCÍA ECHEVERRY, Daniel. Horizontes Geopolíticos Colombianos. Colección de oro del Militar Colombiano. Tomo XXI. Santafé de Bogotá D. C. Imprenta y Publicaciones de las Fuerzas Militares. 1991.

GARCIA NEGRETE, Jorge. Esquema para una investigación Geopolítica. En: Revista Geográfica No.4. Instituto Militar Geográfico. Quito Ecuador.

GÓMEZ BUENDIA, Hernando. La Violencia Contemporánea en Colombia: un punto de vista liberal, el pasado y presente de la violencia en Colombia. Editorial CEREC. Bogotá 1986.

GÓMEZ MASERI, Sergio. Corresponsal. Política. Despejes no pueden ser santuarios para narcos. En: EL TIEMPO. Bogotá, D. C. Sábado 13 de enero de 2001.

GONZÁLEZ ARIAS, José Jairo - MARULANDA ALVAREZ, Elsy. Historias de Frontera. Colonización y guerras en el Sumapáz, CINEP. ISBN-958-644-004-4. Bogotá, 1990. 236 p.

GONZÁLEZ ARIAS, José Jairo. Espacios de exclusión. El estigma de las repúblicas independientes. 1955-1965. Colección sociedad y conflicto. Santafé de Bogotá D. C. Cinep 1992.

26 José Luis Cadena Montenegro 
GONZÁLEZ POSSE, Ernesto. La Frontera como factor de Integración. Intal. Buenos Aires Argentina 1990.230 p.

GONZÁLEZ, Olga L. Paz. La solución es negociada. En: EL ESPECTADOR domingo 11 de febrero de 2001.

GORCE de la, Paul-Marie. El Papel de la ONU, ocupado por la OTAN. Organizaciones Internacionales, Alianzas y Caos Geopolítico: Debatir el papel de la ONU? En: Geopolítica del Caos. Le Monde Diplomatique. Edición Española. Prólogo de Manuel Vázquez Montalbán. Temas de debate. Primera Edición. Madrid, mayo 1999.

GREGORY Derek. MARTÍN Ron and SMITH Graham. Human Geography. Society, Space, and Social Science. University of Minnesota Press 1994.

GUERRERO BELTRAN, Abraham. Archipiélago de San Andrés Territorio Insular de Colombia. En: Revista Boletín de la Sociedad Geográfica de Colombia. Volumen 35 No. 115. Bogotá, 1981.

GUHL, Ernesto. El Hombre y la Geografía. En: Revista Boletín de la Sociedad Geográfica de Colombia. Volumen VIII No.1. Bogotá, marzo 1948.

IBAÑEZ SÁNCHEZ, José Roberto. Democracia, Seguridad y Fuerza Pública. Imprenta y publicaciones de las Fuerzas Militares. Santafé de Bogotá D.C., 1994. 416 p.

. Teoría del Estado - Geopolítica y Geoestratégia. Colección de Oro del Militar Colombiano. Volumen XVII. Imprenta y Publicaciones de las Fuerzas Militares. Santafé de Bogotá, D.C., 1985.

INTAL. Actualización y Adaptación del Proyecto de la Comisión de Cooperación para el Desarrollo de Zonas de Frontera. Buenos Aires Argentina 1993. 45 p.

INTAL. Proyectos de Integración Fronteriza. Buenos Aires Argentina 1992. 18 p.

JAMES, William. El equivalente moral de la guerra. En: La ciudadanía mundial. Santafé de Bogotá. D.C. Planeta. S. A. 1993.

LACOSTE, Yves. La Geografía: un arma para la guerra. Elementos críticos. Editorial Anagrama. Barcelona, 1977.

LANDAZÁBAL REYES, Fernando. El Precio de la Paz. Santafé de Bogotá, D.C. Planeta. ISBN.958614-123-3. noviembre 1985.

. La Hora de la Reflexión. Editorial Temis S.A. Santafé de Bogotá-Colombia, 1997. 198 p.

LEAL BUITRAGO, Francisco (compilador). En busca de la estabilidad perdida. Actores políticos y sociales en los años 90. TM Editores. IEPRI (UN) Colciencias. ISBN 958-601-625-0. Santafé de Bogotá, D.C., agosto de 1995. 331 p.

LONDOÑO, Julio. Los Fundamentos de la Geopolítica. Colección de Oro del Militar Colombiano. Volumen IX. Imprenta y Publicaciones de las Fuerzas Militares. Bogotá, D. C. 1978. 
LÓPEZ TRIGAL, Lorenzo y DEL POZO, Paz Benito. Geografía Política. Ediciones Cátedra S.A. Madrid, 1999.

LUCBERT, Manuel. Geopolítica de Asia Central: India como centro. Capítulo 8 Introducción. En: Geopolítica del Caos. Le Monde Diplomatique. Edición Española. Prólogo de Manuel Vázquez Montalbán. Temas de debate. Primera Edición. Madrid, mayo 1999.

MACHADO, Absalón. La Cuestión Agraria en Colombia a fines del milenio. Bogotá: El Ancora Editores. 1998.

MARTÍNEZ, Pedro. Ordenamiento Territorial en medio de la crisis del estado nacional y de la globalización. La región sur del Valle del Cauca y norte del Cauca. En: Memorias XVI Congreso Colombiano de Geografía. Santiago de Cali. Agosto 2000.

MARULANDA, Iván. Narcotráfico, Autodefensas y Paramilitares en la Patria Boba. Testimonio al borde del abismo. Bogotá, D. C. Folio Ltda. 1990.

MASSIRIS CABEZA, Ángel. Determinantes de los planes de ordenamiento territorial. En: Revista Perspectiva Geográfica No. 2. Primer Semestre de 1998 UPTC-IGAC. Editorial de la Universidad Pedagógica y Tecnológica de Colombia. Tunja Colombia, 1998.

. El Diagnóstico Territorial en la Formulación de Planes de Ordenamiento. En: Revista Perspectiva Geográfica No. 5. Primero y Segundo Semestres de 2000 UPTC-IGAC. Editorial de la Universidad Pedagógica y Tecnológica de Colombia. Tunja Colombia, 2000.

MATTA ALDANA, Luis Alberto. Colombia y las FARC. Origen de la lucha guerrillera. Testimonio del Comandante Jaime Guaraca. Editorial Txalaparta. ISBN 84-8136-118-6. Bogotá, 1999.

MENDEZ, Ricardo. La lógica espacial del capital global. En: Geografía económica.

MENDOZA MORALES, Alberto. Evolución Histórica de las Divisiones Político-Administrativas de Colombia desde 1509 hasta hoy. En: Revista Boletín de la Sociedad Geográfica de Colombia. Volumen 39 Nos. 122-123. Bogotá, 1988 - 1989.

MOLANO, Alfredo. Opinión. Columna de los despejes. En: EL ESPECTADOR. Bogotá, D.C. Domingo 11 de febrero de 2001.

MUNAR P., Carlos. El río Orinoco, límite de la Colonización de los Llanos de Colombia. En: Revista Pensamiento y Acción. Volumen III No.3. Universidad Pedagógica y Tecnológica de Colombia. Ediciones “La Rana y el Águila”. Tunja, enero-marzo 1985.

OSLENDER, Ulrich. Espacializando Resistencia: perspectivas de 'espacio' y 'lugar' en las investigaciones de los movimientos sociales. En: Cuadernos de Geografía. Universidad Nacional de Colombia. Vol. VIII No. 1, 1999. Citando a Lefebvre (1976:31).

PAINTER, Joe. Lecturas en Geografía. En: Política, Geografía y "Geografía Política”. Facultad de Ciencias Humanas. Departamento de Geografía. Santafé de Bogotá: Edición Antonio Florez. Jhon Williams Montoya. Traducción del Artículo por Ovidio Delgado Mahecha. 1998.

PALACIOS MEJIA, Hugo. Introducción a la Teoría del Estado. Editorial Temis. Bogotá, 1965.

28 José Luis Cadena Montenegro 
PARRA-PEÑA, Isidro. El Subesarrollo y la Crisis. En la economía y en la teoría económica. Academia Colombiana de Ciencias Económicas. Editorial Plaza \& Janes. ISBN: 958-14-0133-4. Bogotá, 1986.

PERPIÑÁ y GRAU, Román. Determinantes económico-políticos de los grandes espacios. Editorial Labor, S.A. ISBN.84-335-3329-0. Barcelona, España 1973.

PINZÓN FORERO, Alfonso. La Colonización Militar y el Conflicto Colombo-Peruano. Ediciones ACORE. Volumen I. Editorial Marbella Ltda. Bogotá, D.E., 1990.

QUEVEDO ENCINALES, Jaime. Zona de Despeje - un fraccionamiento de la unidad territorial nacional. En: periódico Fuerza Colombia. Bogotá: Año 1 edición No. 2, julio de 1999.

RAMONET, Ignacio. Las convulsiones del mundo. En: Geopolítica del cáos. Lemonde Diplomatique. Barcelona. España. Editorial Temas de Debate, 1999.

REYES POSADA, Alejandro. Geografía de la Guerra. Estudio de la Universidad Nacional. En: lecturas dominicales de El Tiempo. 17 de octubre de 1999.

REVISTA EJÉRCITO. Más de mil atentados a oleoductos. Santafé de Bogotá D.C. Edición No. 98. Julio - agosto de 1999.

RIVAS MORENO, Gerardo. Bolívar. La Patria es América. Cuadernillos para el Tercer Milenio. Fundación para la Investigación y la Cultura. FICA. Editorial Lealon. ISBN: 958-9091-103. Medellín, 1994.

RODRÍGUEZ R., José Jaime. Paz. Errores y Engaños de un Proceso. Ediciones ACORE Volumen II. Editorial Marbella Ltda. Santafé de Bogotá, D.C., 1991. 265 p.

RUIZ NOVOA, Alberto. Geopolítica y Estrategia - el mar Caribe. En: Revista Boletín de la Sociedad Geográfica de Colombia. Volumen 36 No. 118. Bogotá, 1986.

SAAVEDRA, Juan José. La Zona de Tolerancia. En: El Tiempo, Bogotá, D.C. 29, noviembre, 2000.

SALCEDO LORA, Juan. El Despeje como alternativa de paz y como herramienta de diálogo. En: periódico CONFECORE. Mayo-junio 1999.

SALCEDO, Carlos J. Las futuras comunicaciones en el oriente y sur-oriente colombianos. En: Revista Boletín de la Sociedad Geográfica de Colombia. Volumen 34 No. 114. Bogotá, 1979.

SÁNCHEZ, Gonzalo / PEÑARANDA, Ricardo. Compiladores. Pasado y Presente de la Violencia en Colombia. Segunda Edición. ISBN 958-961-12-5. Santafé de Bogotá: Instituto de Estudios Políticos y Relaciones Internacionales (IEPRI) de la Universidad Nacional de Colombia. 1991. 486 p.

SÁNCHEZ, Joan-Eugeni. Geografía Política. Espacios y Sociedades. Madrid: Síntesis.

SANGUIN, André-Luis. Geografía Política. Elementos de Geografía. Barcelona: Oikos-tau, S.A., 1981.

SANTOS DE ALMEIDA, Milton. La Metamorfosis del Espacio Habitado. Editora Hucitec. Sao Paulo. 1996. 
SANTOS, Milton. DE SOUZA, María A. Silveira María L.. Territorio Globalización y fragmentación. Editorial HUCITEC - ANPUR. Tercera edición. Sao Paulo, 1996.

SANTOS, Milton. La Naturaleza del Espacio. Técnica y Tiempo. Razón y emoción. Editora Hucitec. Sao Paulo, 1996.

SANTOS PICO, Manuel José. La acción directa frente a la subversión. En: Revista Fuerzas Armadas. Vol. LIV. Edición 170. Bogotá, D.C. Imprenta y Publicación de las Fuerzas Militares.

SMALL Gretchen y SMALL Dennis. El Complot para aniquilar a las Fuerzas Armadas y a las naciones de Iberoamérica. EIR-Resumen Ejecutivo. ISBN: 0-943-235-15-4. Washington D.C. 1997.

TAYLOR, Peter J. Geografía Política - Economía-Mundo, Estado-Nación y Localidad. Trama Editorial. Primera Edición en español. Madrid España 1994.

TZU, Sun. El Arte de la Guerra de Wu Sun. Tercera Edición. Santafé de Bogotá D.C. Tercer Mundo S.A. Elektra Editores. 1997.

UNWIN, Tim. El lugar de la Geografía. Editorial Cátedra. Traducción de Jerónima García Bonafé. Madrid España. 1995.

VALENCIA TOVAR, Alvaro. Inseguridad y Violencia en Colombia. Primera Edición. Universidad Sergio Arboleda. Fondo de Publicaciones. Julio de 1997. 242 p.

VARGAS LLERAS, Germán. El memorial de Vargas. En EL TIEMPO. Primer plano. Bogotá, D.C. jueves 4 de octubre de 2001.

VASCO, Mauricio. Grupo de Río. Fortalecimiento de las Administraciones Públicas Nacionales para la Integración Regional. Informe final. Montevideo, junio de 1995. 88 p.

VÁSQUEZ SÁNCHEZ, Jaime. Estrategias Geopolíticas y posibilidades para un nuevo ordenamiento territorial en el medio rural. En: Memorias XVI Congreso Colombiano de Geografía. Santiago de Cali: Agosto 2000 .

VÁSQUEZ, R.H. El proceso de urbanización en la historia de Colombia. ESAP. Santafé de Bogotá: 1978.

VILLAMARIN PULIDO, Luis Alberto. El Cartel de las FARC. Segunda Edición. Ediciones El Faraón. ISBN 958-33-0380-1. Bogotá, octubre 1996. 235 p.

30 José Luis Cadena Montenegro 